\title{
The Effect of Interactive Multimedia And Illustrated Booklet On Knowledge, Attitude, And Behavior In Preventing Lower Back Pain Among Working Nurses: A Randomized Controlled Trial
}

Nahid Zarifsanaiey ( $\nabla$ nzarifsanaee@gmail.com )

Shiraz University of Medical Sciences https://orcid.org/0000-0002-1297-8271

\section{Zahra Yazdani}

Shiraz University of Medical Sciences

Zahra karimian

Shiraz University of Medical Sciences

Hadi Raeisi Shahraki

Shahrekord University of Medical Science

Farahnaz Ghaffarinejad

Shiraz University of Medical Sciences

\section{Research Article}

Keywords: Knowledge, Attitude, Behavior, Multimedia, Illustrated Booklet, Low Back Pain

Posted Date: August 13th, 2021

DOI: https://doi.org/10.21203/rs.3.rs-682719/v1

License: (c) (i) This work is licensed under a Creative Commons Attribution 4.0 International License.

Read Full License 


\section{Abstract}

Background: The present study compared interactive multimedia and illustrated booklet methods on knowledge, attitude, and behavior improvement in preventing lower back pain among nurses.

Methods: In this single-blind randomized controlled trial, 153 eligible nurses working in three hospitals during 2019 were enrolled. The hospitals were randomly allocated into three parallel groups: interactive multimedia $(n=55)$, illustrated booklet $(n=55)$, and t control $(n=43)$ groups. The primary and secondary outcomes were the assessment of behavior, knowledge, and attitude at baseline, one, and four weeks after the intervention.

Results: Regarding one week and four weeks after the intervention, knowledge and behavior score was significantly higher in the illustrated booklet group than that of the multimedia group $(P<0.001)$. In addition, the mean score of attitude was considerably higher in the interactive multimedia compared to the booklet group one week and four weeks after the intervention $(P=0.002)$.

Conclusion: A combination of the illustrated booklet and interactive multimedia methods can improve nurses' knowledge, attitude, and behavior in preventing lower back pain.

Trial registration: This trial was respectively registered.

ClinicalTrials.gov Identifier: NCT04610073

Date of registration: Oct 302020

(https://clinicaltrials.gov/ct2/show/NCT04610073?term=zarifsanaiey\&draw=1\&rank=2)

\section{Background}

Lower back pain (LBP) is considered the first cause of restricting occupational activity before 45 years and the third cause along with respiratory diseases and traumatic injuries in the age group of 45-64 years [1]. Based on the previous studies, musculoskeletal disorders, especially LBP, are directly associated with specific jobs in the medical field [2]. Nursing is considered as one of the highest-ranking among the five jobs leading to LBP. LBP occurs due to some factors such as long night shifts [3], lifting patients, prolonged standing [4], lifting equipment, and mechanical instruments[5]. LBP results in increased absenteeism from the workplace, increased medication errors, early retirement, changing workplace, slower services, and even job change [2,6]. Many medical interventions are conducted to reduce the adverse effects of LBP, including medication therapy, physical therapies, complete rest, surgery, and complementary therapies, and training [7].

Training the healthcare team, especially nurses, can increase their knowledge, attitude, and skills in preventing LBP, resulting in providing services to patients more efficiently. Hence, choosing an appropriate 
educational method plays a significant role in learning and enhancing the individuals' willingness to change their health-related behaviors [8].

Self-directed learning techniques such as multimedia and educational booklets have many applications in nursing. Educational multimedia can provide learners with much better learning due to words, images, animation, and sound [9]. However, access to educational technology and software compatible with educational facilities and conditions is considered the limitations students may face [10]. On the other hand, educational booklets have been used for many years in nursing education. The joy of holding and reading a booklet, underlining and marking essential points, the tangibility of topics, and the book-reading habit are considered the benefits of booklets. However, the time consumed to edit and produce booklets, high costs, and lack of possibility to change the color, margin, size, and font of the texts according to the person's taste are among its disadvantages [11].

A large number of studies have been conducted to compare the multimedia and conventional methods such as booklets and indicated that multimedia plays a more significant effect than conventional education on knowledge, skill, and self-efficacy [12], depression and anxiety [13], the severity of pain, overdramatization of pain, and coping with pain [14], as well as knowledge and skills among the patients [15]. Given the increasing statistics of LBP among nurses and the fact that no study has been conducted in this area in Shiraz University of Medical Sciences, the present study aimed to compare the effects of interactive multimedia and illustrated booklet methods as two LBP-prevention educational methods.

\section{Methods}

\section{Design}

The present study was a single-blinded three-arm parallel design randomized controlled trial with equal group allocation. The study adheres to CONSORT 2010 guidelines (Additional file 1).

\section{Participants}

Eligibility criteria for participants:

The inclusion criteria were all nurses working in hospitals affiliated with Shiraz University of Medical Sciences with a minimum education level of bachelor's degree in nursing, willingness to participate, completion of an informed consent form, and minimum knowledge of working with computers. Those with congenital abnormalities, LBP, history of back surgery, and history of trauma to the back, pregnancy, and severe osteoporosis were excluded. All those unwilling to continue their cooperation and those with extended leave of absence during the study were excluded.

\section{Setting}

The population included the nurses working in the hospitals affiliated with Shiraz University of Medical Sciences Shiraz, Iran, during June-December 2019. 


\section{Intervention}

The intervention groups received LBP educational content using interactive multimedia (Group 1) and illustrated booklet (Group 2). However, no intervention was performed in the Wait-list control group.

\section{Educational content design}

First, the contents related to LBP prevention were prepared through books reviews and credible domestic and foreign articles [5-8]. The topics were related to an introduction to LBP, information about LBP prevention methods such as correctly sitting, sleeping, walking, sitting at the desk, working with the computer, lifting equipment and moving patients correctly, and correct way of exercising to prevent LBP. The educational contents were reviewed and evaluated by ten faculty members from rehabilitation and nursing departments, and necessary corrections were made. Then, the content was divided into pieces, each containing the learning goals, educational paragraphs, relevant images and graphs, questions and assignments, and finally summary, relevant references, and a final exam. Then, the researchers developed the interactive multimedia and illustrated booklet based on Mayer multimedia principles and standards [16]. The topics were identical in the illustrated booklet and interactive multimedia. Finally, the software and the booklet were confirmed by two experts after technical and content evaluation, which was made available for the participants through a DVD and printed booklet formats.

After obtaining permission from the university research deputy and heads of public hospitals in Shiraz, the researchers entered the study setting. First, the study objectives were explained to participants in a meeting, and after obtaining written informed consents, eligible subjects completed the pretest knowledge, attitude, and behavior questionnaire. Then, illustrated educational booklet or interactive multimedia were made available to intervention groups. The questionnaire was completed by all three groups a week after completing the training and then a month afterward.

\section{- Interactive Multimedia group:}

All eligible nurses allocated to this group received the LBP prevention education through DVD version and have one week to study the content. It features 35 minutes of animation that included textual, pictorial, and spoken contents, which were prepared according to educational scenarios. The learning goals, paragraphs, images, related graphs, and questions were designed for each section. The questions were interactive to select one of the answers in the lesson, and then the system would provide them with the necessary feedback. Regarding correct answers, learners remained on the main path of the task, and the supplementary data tab became activated for further information.

Regarding incorrect answers, learners received sufficient explanations after feedback and then transferred to the additional information section. During the lesson, nurses were able to answer questions until reaching the correct answer. After providing the right solution, they were led to the main path and eventually reached a common terminal path. 
Illustrated Booklet: The eligible nurses in this group received Illustrated Booklet and have one week to study the contents. Educational items containing written and visual contents were color printed to become an attractive booklet with illustrations in 22 A5-size pages as many reprints as subjects in the control group. The end of each section and each lesson contained questions and tests, and learners could answer them and compare their answers with those provided on the last page of the booklet. All educational multimedia contents designed in animation, such as correct moving, standing, sleeping, and sitting techniques, were shown stage-by-stage in the booklet in written forms and color still images (Table 1).

Table 1

Comparison of Interactive multimedia and Illustrated Booklet features

\begin{tabular}{|lllllll|}
\hline Education & Text & Voice & Picture & Animation & question & Total volume \\
\hline Multimedia & $*$ & $*$ & $*$ & $*$ & $*$ & 30 minutes \\
\hline Illustrated Booklet & $*$ & - & $*$ & -- & $*$ & 15 pages \\
Wait-list control group & & & & &
\end{tabular}

No intervention was performed in the control group. It is worth noting that the educational content was made available to the control group at the end of the study.

\section{Outcomes}

Behavior was considered the primary outcome measure. The secondary outcome measures were the nurses' knowledge and attitude scores to prevent low back pain at baseline, one, and four weeks after interventions in the intervention and control group. To collect data, we made a questionnaire for assessing nurses' knowledge, attitude, and behavior for preventing LBP, the features of which are as follows.

Demographic details (age, gender, marital status, height, weight, history of LBP, and history of surgery or underlying diseases)

- Knowledge (10 four-option questions with each correct answer scoring one point, an incorrect answer zero, and total score between 0 and 10 points)

- Attitude (18 questions based on a six-point Likert scale from totally agree (6 points) to disagree (1 point) with a total score between 18 and 88 points

- Behavior (19 questions based on a six-point Likert scale from always (6 points) to never (1 point) with a minimum score of 19 points and a maximum of 114

\section{Validity and reliability of data collection tool}

Twenty experts were asked to comment on tool development, nursing, and rehabilitation to assess the face and content validity. The quantitative face validity was evaluated by determining grammar and the 
use of appropriate words. The quality of questions in the knowledge section was assessed in terms of "simplicity, "relevance," and "clarity." Regarding the attitude and behavior sections, the "item impact" method was used as follows.

Impact score $=$ Frequency $(\%) \times$ importance

And $\mathrm{CVI}=0.94$ and $\mathrm{CVR}=0.8$.

Construct validity was confirmed using confirmatory factor analysis in SMART-PLS 3.2.4.

- Measurement model fit criteria

The reliability of items related to the knowledge section was confirmed using the test-retest method among 60 nurses with two-week intervals $(r=0.54, P<0.001)$. The attitude and behavior section was approved by using Cronbach's alpha and Composite Reliability (CR) methods, and the results were 0.92 and 0.925 for attitude and 0.94 and 0.95 for behavior, respectively. Average Variance Extracted was found regarding convergent validity, which was found to be a 0.51 in attitude, and 0.50 in behavior dimensions, indicating appropriate convergent validity. Finally, Divergent validity was confirmed using the FornellLarcker test. It is worth noting that the participants spent 15 minutes to fill the questionnaire. The research assistant provided a specific ID for each participant for the following the research process

\section{Sample Size}

Based on the preliminary sample data (60 nurses), as well as considering the difference in the knowledge scores of multimedia and booklet groups $(M=1.5, S D=0.1)$, and type I and II errors ( 0.05 and 0.10$)$, the sample size was 126 nurses which increased to 190 regarding the possible withdrawal. By adding 60 nurses from the pilot study (20 in each group), 130 other participants were selected to reach the required sample size.

$N=\frac{\left(s_{1}^{2}+s_{2}^{2}\right)\left(Z_{1-\frac{\alpha}{2}}+Z_{1-\beta}\right)^{2}}{\left(\mu_{1}-\mu_{2}\right)^{2}}$

\section{Randomization}

To prevent contamination between intervention and controls, the hospital used as the unit of randomization (rather than nurse). First, three hospitals were selected based on convenience sampling, which was randomly allocated into three "parallel" groups; intervention 1 (receiving interactive multimedia), intervention 2 (receiving illustrated booklet), and control (no intervention) groups using a random number table. These hospitals were similar in terms of specialty and workload and working wards of the nurses. Then, three wards of each hospital, including surgery, orthopedics, and emergency, which were similar in terms of nurses' workload, were purposefully selected. The eligible nurses who were willing to participate were selected. The nurses were screened until 60 participants were recruited from 
each hospital during June-December 2019. The randomization was conducted by an assistant researcher who was not involved in the research protocol.

\section{Blinding}

In this single-blinded randomized trial, the nurses, and the samples were blinded to intervention and control groups.

\section{Statistical methods}

The collected data were analyzed in SPSS- 21 by using descriptive and inferential statistical tests. Repeated measure analysis was used to compare the pretest and posttest results, ANOVA and LSD posthoc tests for intergroup comparison, and Chi-square test to assess the relationship between qualitative variables. In the observed significant interaction between time and group, separate repeated measure analysis was performed to determine the effect of time in each group. P-value $<.05$ was considered as the significance level.

\section{Ethical consideration}

The study was started after it was approved by the local ethics committee of Shiraz University of Medical Sciences (decree code: IR.SUMS.REC.1398.040), and necessary coordination was made with the teaching hospitals of Shiraz University of Medical Sciences. First, the study objectives were explained to the participants in a meeting, and written informed consent was obtained. To maintain anonymity, no names were written on the questionnaires, and completed questionnaires were encoded by a research assistant to prevent possible errors. To observe ethical principles, the participants were assured of their voluntary participation and withdrawal at any time. Finally, the researcher prepared a written software installation guide and made it available to the multimedia group.

\section{Results}

Of the 180 eligible NURSES who started the study, 153 (85\%) nurses, including 43 in the control group, 55 in the illustrated booklet group, and 55 in the multimedia group, completed it. A total of 27 participants declined to participate in the follow-up assessment and were excluded from the study $(17,5$, and 5 nurses in the control, booklet, and multimedia groups) (Fig. 1).

Participants' demographic characteristics are shown in Table 2. 
Table 2

Demographic characteristics of nurses among different groups

\begin{tabular}{|c|c|c|c|c|c|}
\hline Variable & Subgroup & $\begin{array}{l}\text { Control }(n= \\
43)\end{array}$ & $\begin{array}{l}\text { Booklet }(n= \\
55)\end{array}$ & $\begin{array}{l}\text { Multimedia ( } \mathrm{n}= \\
55)\end{array}$ & $\begin{array}{l}\mathrm{P} \text { - } \\
\text { value }\end{array}$ \\
\hline \multirow[t]{2}{*}{ Gender } & Female & $16(37.2)$ & $13(23.6)$ & $17(30.9)$ & \multirow[t]{2}{*}{0.34} \\
\hline & Male & $27(62.8)$ & $42(76.4)$ & $38(69.1)$ & \\
\hline \multirow[t]{2}{*}{ Marital status } & Single & $20(46.5)$ & $32(58.2)$ & $31(56.4)$ & \multirow[t]{2}{*}{0.48} \\
\hline & Married & $23(53.5)$ & $23(41.8)$ & $24(43.6)$ & \\
\hline \multirow{5}{*}{$\begin{array}{l}\text { Employment } \\
\text { status }\end{array}$} & Contractual & $7(16.3)$ & $12(21.8)$ & $15(27.3)$ & \multirow[t]{5}{*}{0.36} \\
\hline & $\begin{array}{l}\text { Corporate } \\
\text { recruitment }\end{array}$ & $4(9.3)$ & $4(7.3)$ & 8 (14.5) & \\
\hline & Temporary & $4(9.3)$ & $4(7.3)$ & $5(9.1)$ & \\
\hline & $\begin{array}{l}\text { Government } \\
\text { employment }\end{array}$ & $19(44.2)$ & 15 (27.3) & $13(23.6)$ & \\
\hline & Recruitment plan & 9 (20.9) & $20(36.4)$ & $14(25.5)$ & \\
\hline \multirow{3}{*}{$\begin{array}{l}\text { Work } \\
\text { experience }\end{array}$} & $<10$ years & $23(53.5)$ & $36(65.4)$ & $38(69.1)$ & \multirow[t]{3}{*}{0.17} \\
\hline & $10-20$ years & $18(41.9)$ & 15 (27.3) & $17(30.9)$ & \\
\hline & $>20$ years & $2(4.7)$ & $4(7.3)$ & $0(0.0)$ & \\
\hline Weight (kg) & & $65.0 \pm 9.4$ & $65.4 \pm 10.8$ & $68.3 \pm 13.9$ & 0.28 \\
\hline BMI & & $23.4 \pm 2.7$ & $23.8 \pm 2.9$ & $24.4 \pm 3.7$ & 0.16 \\
\hline
\end{tabular}

The results indicated that the participants $(n=153)$ in the intervention and control groups were matched in terms of demographic variables such as gender $(P=0.34)$, marital status $(P=0.48)$, employment status $(P=0.36)$, weight $(P=0.28)$, and $\mathrm{BMI}(P=0.16)$.

\section{Knowledge Score}

The mean score of knowledge about preventing LBP before the intervention was not statistically significant $(P=0.13)$, while it was significantly higher in illustrated educational booklet group a week later $(P<0.001)$ and four weeks after the intervention $(P<0.001)$ (Fig. 2).

In addition, the knowledge score in the interactive multimedia group was significantly higher than the control group (no intervention) a week later and four weeks after the intervention $(P<0.001)$. At the same time, it was considerably lower than the booklet group $(P<0.001)$. Based on the results of the repeated measure analysis, the time had a significant effect on the level of knowledge both in the booklet $(\mathrm{P}<$ $0.001)$ and multimedia $(P<0.001)$ groups (Table 3$)$. 
Table 3

Between and within-group comparison of multimedia, booklet, and control groups in terms of knowledge, attitude, and behavior

\begin{tabular}{|c|c|c|c|c|c|c|c|}
\hline Variable & Group & Pretest** & Posttest ${ }^{\#}$ & $\begin{array}{l}\text { Follow } \\
\text { up\# }\end{array}$ & $\begin{array}{l}\text { Time } \\
\text { effect } \\
\text { P- } \\
\text { value* }\end{array}$ & $\begin{array}{l}\text { Group } \\
\text { effect } \\
\text { P-value* }\end{array}$ & $\begin{array}{l}\text { Time group } \\
\text { effect } \\
\text { P-value* }\end{array}$ \\
\hline \multirow[t]{3}{*}{ Knowledge } & Control & $4.5 \pm 1.3$ & $4.8 \pm 1.5$ & $\begin{array}{l}5.0 \pm \\
1.5\end{array}$ & 0.06 & \multirow[t]{3}{*}{$<0.001$} & \multirow[t]{3}{*}{$<0.001$} \\
\hline & Booklet & $5.0 \pm 1.7$ & $7.3 \pm 1.1$ & $\begin{array}{l}7.4 \pm \\
1.2\end{array}$ & $<0.001$ & & \\
\hline & Multimedia & $4.4 \pm 2.0$ & $5.6 \pm 2.0$ & $\begin{array}{l}6.3 \pm \\
1.5\end{array}$ & $<0.001$ & & \\
\hline \multicolumn{2}{|c|}{$\begin{array}{l}\text { Between group } \\
\text { comparison P value }\end{array}$} & 0.13 & $<0.001$ & $<0.001$ & & & \\
\hline \multirow[t]{3}{*}{ Attitude } & Control & $\begin{array}{l}99.0 \pm \\
14.5\end{array}$ & $\begin{array}{l}96.2 \pm \\
10.7\end{array}$ & $\begin{array}{l}96.0 \pm \\
10.2\end{array}$ & 0.03 & \multirow[t]{3}{*}{0.11} & \multirow[t]{3}{*}{$<0.001$} \\
\hline & Booklet & $\begin{array}{l}100.4 \pm \\
16.4\end{array}$ & $\begin{array}{l}94.2 \pm \\
8.2\end{array}$ & $\begin{array}{l}91.7 \pm \\
7.4\end{array}$ & $<0.001$ & & \\
\hline & Multimedia & $\begin{array}{l}89.0 \pm \\
15.5\end{array}$ & $\begin{array}{l}93.0 \pm \\
14.9\end{array}$ & $\begin{array}{l}94.1 \pm \\
12.8\end{array}$ & 0.002 & & \\
\hline \multicolumn{2}{|c|}{$\begin{array}{l}\text { Between group } \\
\text { comparison P value }\end{array}$} & 0.001 & 0.06 & $<0.001$ & & & \\
\hline \multirow[t]{3}{*}{ Behavior } & Control & $\begin{array}{l}70.1 \pm \\
16.1\end{array}$ & $\begin{array}{l}69.6 \pm \\
14.3\end{array}$ & $\begin{array}{l}69.4 \pm \\
14.3\end{array}$ & 0.41 & \multirow[t]{3}{*}{$<0.001$} & \multirow[t]{3}{*}{$<0.001$} \\
\hline & Booklet & $\begin{array}{l}69.7 \pm \\
19.7\end{array}$ & $\begin{array}{l}80.1 \pm \\
12.5\end{array}$ & $\begin{array}{l}84.4 \pm \\
14.4\end{array}$ & $<0.001$ & & \\
\hline & Multimedia & $\begin{array}{l}61.7 \pm \\
18.1\end{array}$ & $\begin{array}{l}66.9 \pm \\
18.1\end{array}$ & $\begin{array}{l}69.1 \pm \\
15.8\end{array}$ & $<0.001$ & & \\
\hline \multicolumn{2}{|c|}{$\begin{array}{l}\text { Between group } \\
\text { comparison P value }\end{array}$} & 0.03 & $<0.001$ & $<0.001$ & & & \\
\hline \multicolumn{8}{|c|}{ * Repeated measurement analysis } \\
\hline \multicolumn{8}{|c|}{ ** Independent T-test } \\
\hline \multicolumn{8}{|c|}{ \# Analysis of covariance (considering pre-test as covariate) } \\
\hline
\end{tabular}

The results presented in Table 3 show that although both educational methods could affect the nurses' knowledge, the educational booklet had a more significant effect.

\section{Attitude Score}


ANCOVA was performed to compare the mean scores of attitude toward preventing LBP a week later and four weeks after the intervention with pretest adjustment. Although no significant difference was observed among the attitude score of groups a week after the intervention $(P=0.06)$, the attitude level in the booklet group was significantly lower $(P=0.04)$ than the control group at four weeks after the intervention (Fig. 3).

Table 3 compares the difference in mean scores of attitude in multimedia, booklet, and control groups. Based on the results, the participants' attitude in booklet and multimedia groups could improve significantly over time, which was more significant in the multimedia group than the booklet group $(\mathrm{P}<$ 0.001).

\section{Behavior Score}

Results of ANCOVA in Table 3 indicated that both of the interventions led to a significant increase in mean scores of behavior in preventing LBP in the booklet $(P<0.001)$ and multimedia groups $(P<0.001)$. In addition, the improvement was significantly more significant in the booklet group compared to multimedia even after adjusting the pretest score $(P<0.001)$.

Regarding the results of the LSD test, a significant difference was reported between booklet-control and multimedia-booklet in the nurses' behavior $(P<0.001, P<0.001)$. Therefore, both multimedia and booklet educational methods significantly affected the nurses' behavior, but the booklet had a more significant effect (Fig. 4).

It is worth noting that any harm or unintended effect was observed in the group.

\section{Discussion}

The present study compared the effects of interactive multimedia and illustrated booklet methods on the nurses' knowledge, attitude, and behavior to prevent LBP. Based on the results, both methods improved knowledge, attitude, and behavior among the nurses concerning LBP. However, the booklet had a more significant effect on improving behavior and increasing knowledge. In comparison, multimedia had a more substantial impact on the nurses' attitude toward preventing chronic LBP.

The result of the present study is consistent with that of Piri et al. [11], in which booklet and multimedia could significantly influence students' awareness and attitude about controlling nosocomial infections. In addition, Fary et al. indicated that both of these educational methods led to better learning among physiotherapy students [12]. Momennasab et al. compared the effects of booklet and multimedia methods on teachers' knowledge on preventing high-risk behaviors and reported that both approaches could affect teachers' knowledge [13].

On the other hand, some studies evaluated the greater effectiveness of multimedia compared to booklet method in pregnant women's knowledge of pain management [14], nursing students' learning practical skills [15], patients with type II diabetes [16], and training patients undergoing arthroscopy in which 
multimedia education leads to more effective learning [17]. According to experts, adding images to the text in booklets can contribute to learning among students [18].

In the present study, both multimedia (combination of sound, text, images, and animation) and illustrative booklet (combination of text and pictures) improved nurses' learning and behavior regarding preventing LBP after education. Because these methods provided the learners the possibility of flexible learning in terms of time, place, and speed of learning, students can achieve mastery in a piece of specific knowledge and skill with practice and repetition [19]. However, the illustrated booklet had a more significant effect on nurses' knowledge and behavior regarding LBP prevention. Some experts believe that multimedia can quickly fill people's working memory due to its rich content. However, the fixed images displaying a process stage-by-stage make the individual actively process the pictures and follow them at their speed. While static images do not increase the cognitive load, illustrative booklets help learners easily connect with the content, compare its different parts, and create long-term learning using simple pictures that teach a skill or content stage-by-stage [18].

A positive attitude toward education and educational materials plays a significant role in learning and improving behaviors [20], considering why the participants' attitude was evaluated. Based on the results, nurses' attitudes toward preventing LBP improved in the interactive multimedia group after intervention. In another study, Weng et al. assessed the effectiveness of multimedia education in enhancing the students' attitudes and concluded that multimedia could be an effective way for improving learners' attitude [21]. Mohamed et al. reported that multimedia has a positive and significant effect on nurses' attitudes toward health assessment [22]. Educational multimedia can motivate learners and create a positive attitude by using attractive and appropriate graphics and animations, interactive questions, and feedbacks

Regarding study limitations, for future research, it is recommended that interactive multimedia and illustrative booklet be compared for a longer time and with a larger sample size to achieve more precise measurement of the level of knowledge, attitude, and behavior to prevent lower back pain in working nurses.

\section{Conclusion}

In general, the LBP prevention program, through both interactive multimedia and illustrative booklet, can increase knowledge, attitude, and behavior among working nurses to prevent chronic LBP. Accordingly, it is recommended to integrate illustrative booklet and interactive multimedia into nursing education since it can improve nurses' knowledge, attitude, and behavior to prevent lower back pain.

\section{Abbreviations}

LBP: Lower back pain

LSD: Least Significant Difference

Page $11 / 18$ 
ANOVA: Analysis of Variance

CVI: Content validity index

CVR: content validity ratio

CR: Composite Reliability

GUI: graphic user interface

CD: Compact disc

\section{Declarations}

- Ethics approval and consent to participate

The present study was approved by the ethics committee of Shiraz University of Medical Sciences (decree code: IR.SUMS.REC.1398.040). The basis and necessary information about the study objectives and method were given to all participants before commencement of the study, and written informed consents were obtained from them. Participants were assured of the confidentiality of data and that only general statistics would be presented.

- Consent for publication

Not applicable

- Availability of data and materials

The data that support the findings of this study are available from the corresponding author on request.

- Competing interests

The authors declare that they have no competing interests.

- Financial Support

The authors would like to thank the Vice-chancellor of Research at Shiraz University of Medical Sciences, Shiraz, Iran, for their financial support (grants No. 18330).

- Authors' contributions

NZ, ZY, and ZK devised the study concept, designed the study, supervised the intervention, data collection, and analysis, participated in the coordination of the research, and critically revised the manuscript. MG \& HRS collected data, ran the study intervention, participated in the study concept, performed the analyses, and revised the manuscript. All authors have read and approved the content of the manuscript. 
- Acknowledgments

This article was the result of a master's thesis research project (decree code: 97-01-01-17903) at Shiraz University of Medical Sciences. We are grateful of the research counselor of Shiraz University of Medical Sciences (SUMS) for supporting this study and the Clinical Research Development Centre of SUMS for the statistical analysis. We also wish to thank the nurses in Trauma Center, Chamran, and Namazi hospitals for their honest cooperation and help in conducting the present study.

\section{References}

1. Heidari M, Borujeni MG, Rezaei P, Abyaneh SK. Work-related musculoskeletal disorders and their associated factors in nurses: A cross-sectional study in iran. Malaysian J Med Sci. 2019;26(2):12230.

2. Driscoll T, Jacklyn G, Orchard J, Passmore E, Vos T, Freedman G, et al. The global burden of occupationally related low back pain: Estimates from the Global Burden of Disease 2010 study. Ann Rheum Dis. 2014;73(6):975-81.

3. Nicholl BI, Sandal LF, Stochkendahl MJ, McCallum M, Suresh N, Vasseljen O, et al. Digital Support Interventions for the Self-Management of Low Back Pain: A Systematic Review. J Med Internet Res [Internet]. 2017 [cited 2019 Dec 28];19(5):e179. Available from:

http://www.ncbi.nlm.nih.gov/pubmed/28550009.

4. Suni JH, Rinne M, Kankaanpää M, Taulaniemi A, Lusa S, Lindholm H, et al. Neuromuscular exercise and back counselling for female nursing personnel with recurrent non-specific low back pain: study protocol of a randomised controlled trial (NURSE-RCT). BMJ Open Sport Exerc Med. 2016 Mar;2(1):e000098.

5. Satpute K, Hall T, Bisen R, Lokhande P. The Effect of Spinal Mobilization With Leg Movement in Patients With Lumbar Radiculopathy-A Double-Blind Randomized Controlled Trial. Arch Phys Med Rehabil. 2019 May 1;100(5):828-36.

6. Pakbaz M, Hosseini MA, Aemmi SZ, Gholami S. Effectiveness of the back school program on the low back pain and functional disability of Iranian nurse. J Exerc Rehabil. 2019 Feb 1;15(1):134-8.

7. Steffens D, Maher CG, Pereira LSM, Stevens ML, Oliveira VC, Chapple M, et al. Prevention of lowback pain a systematic review and meta-Analysis. Vol. 176: JAMA Internal Medicine. American Medical Association; 2016. pp. 199-208.

8. Suman A, Schaafsma FG, Bamarni J, Van Tulder MW, Anema JR. A multimedia campaign to improve back beliefs in patients with non-specific low back pain: a process evaluation. BMC Musculoskelet Disord. 2017 May 18;18(1):1-13.

9. Bello GA, Oludele LY, Ademiluyi AB. IMPACT OF INFORMATION, AND COMMUNICATION TECHNOLOGY ON TEACHING AND LEARNING. Niger J Bus Educ. 2018;3(1):201-9.

10. Okeyo ILA, Dowse R. An illustrated booklet for reinforcing community health worker knowledge of tuberculosis and facilitating patient counselling. African J Prim Heal Care Fam Med. 2018 May 
24;10(1).

11. Piri A, Sabzevari S, Borhani F. Comparison the Effect of Two Education Method "Electronic and Lecture Education of Pain Management" on Knowledge and Attitude Regarding Pain in Nursing Student at Zabol and Zahedan Medical University in 2014. Futur Med Educ J. 2015;5(3):29-33.

12. Fary RE, Slater H, Chua J, Ranelli S, Chan M, Briggs AM. Policy-into-practice for rheumatoid arthritis: Randomized controlled trial and cohort study of E-learning targeting improved physiotherapy management. Arthritis Care Res. 2015 Jul 1;67(7):913-22.

13. Momennasab M, Alimohammadi I, Hosseiny FN, Magharei M. The effect of interactive multimedia education on knowledge and attitude of high school teachers about prevention of health-risk behaviors. Int J High Risk Behav Addict. 2018 Dec 1;7(4).

14. Abbasi P, Mohammad-Alizadeh Charandabi S, Mirghafourvand M. Comparing the Effect of Educational Software and Booklet on Knowledge Level Regarding Labor Pain Management: A Randomized Controlled Clinical Trial. Int J Women's Heal Reprod Sci [Internet]. 2017 Jun 19 [cited 2019 Dec 28];5(3):218-23. Available from: http://ijwhr.net/text.php?id=216.

15. George PP, Papachristou N, Belisario JM, Wang W, Wark PA, Cotic Z, et al. Online eLearning for undergraduates in health professions: A systematic review of the impact on knowledge, skills, attitudes and satisfaction. J Glob Health. 2014;4(1).

16. Huang MC, Hung CH, Yu CY, Berry DC, Shin SJ, Hsu YY. The effectiveness of multimedia education for patients with type 2 diabetes mellitus. J Adv Nurs. 2017 Apr;73(4)(1):943-54.

17. Cornoiu A, Beischer AD, Donnan L, Graves S, De Steiger R. Multimedia patient education to assist the informed consent process for knee arthroscopy. ANZ J Surg. 2011 Mar;81(3):176-80.

18. Mayer RE. Using multimedia for e-learning. J Comput Assist Learn [Internet]. 2017 Oct [cited 2020 Feb 1];33(5):403-23. Available from: http://doi.wiley.com/10.1111/jcal.12197.

19. Burge E, Campbell Gibson C, Gibson T. Flexible Pedagogy, Flexible Practice.

20. Najafi Ghezeljeh T, Mohammad Aliha J, Haghani H, Javadi N. Effect of education using the virtual social network on the knowledge and attitude of emergency nurses of disaster preparedness: A quasi-experiment study. Nurse Educ Today. 2019 Feb;1:73:88-93.

21. Weng F, Ho HJ, Yang RJ, Weng $\mathrm{CH}$. The influence of learning style on learning attitude with multimedia teaching materials. Eurasia J Math Sci Technol Educ. 2019;15(1).

22. Mohamed L, Ismail N. EFFECT OF INSTRUCTIONAL MULTIMEDIA METHODS ON LEARNING OUTCOMES AMONG NURSING. STUDENTS IN SELECTED TOPIC OF HEALTH ASSESSMENT. Int Acad J Heal [Internet]. [cited 2020 Feb 1];1(2):11-29. Available from: http://www.iajou.

\section{Figures}




\section{Enrollment}

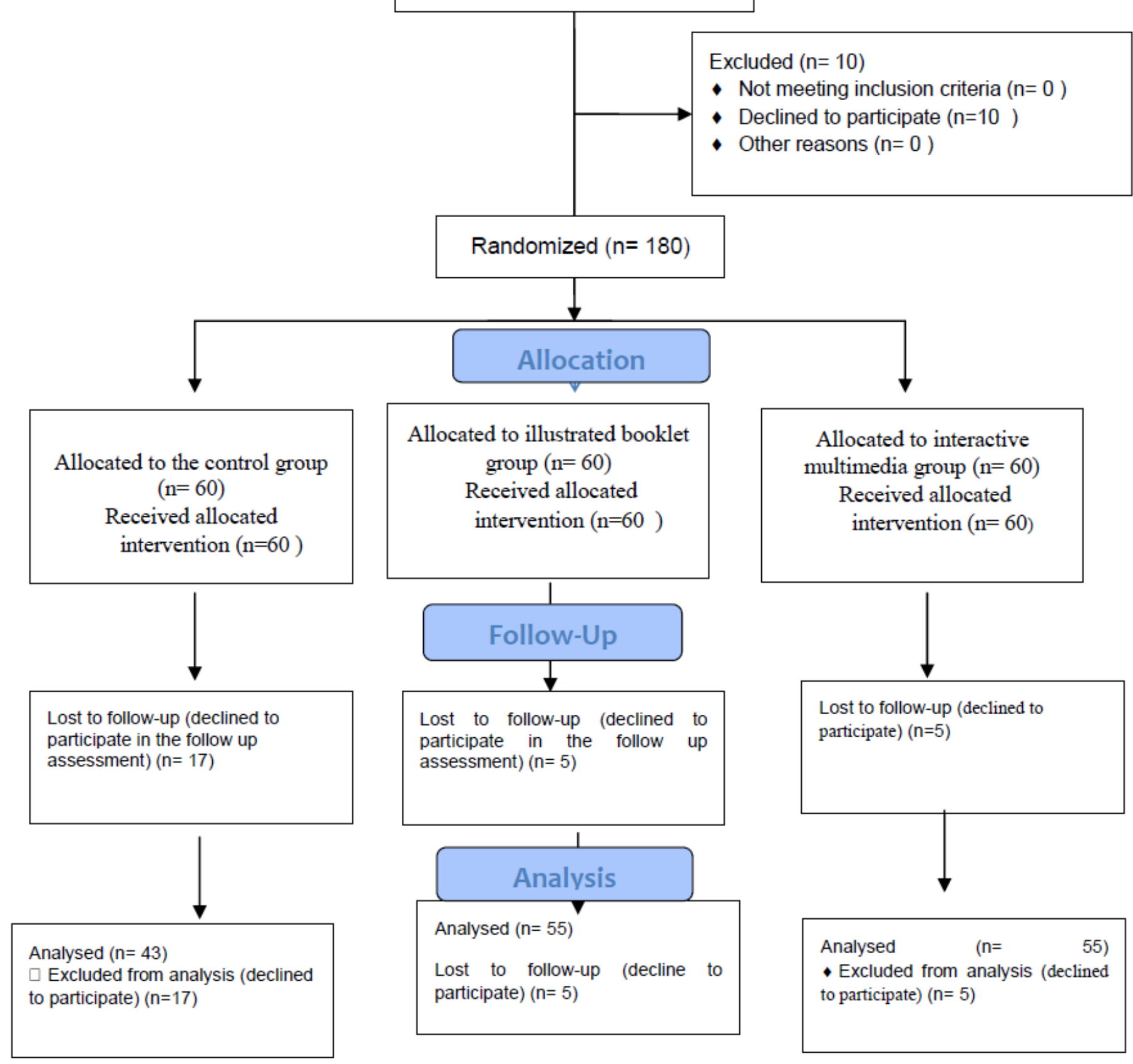

\section{Figure 1}

The patient's recruitment flow diagram. 


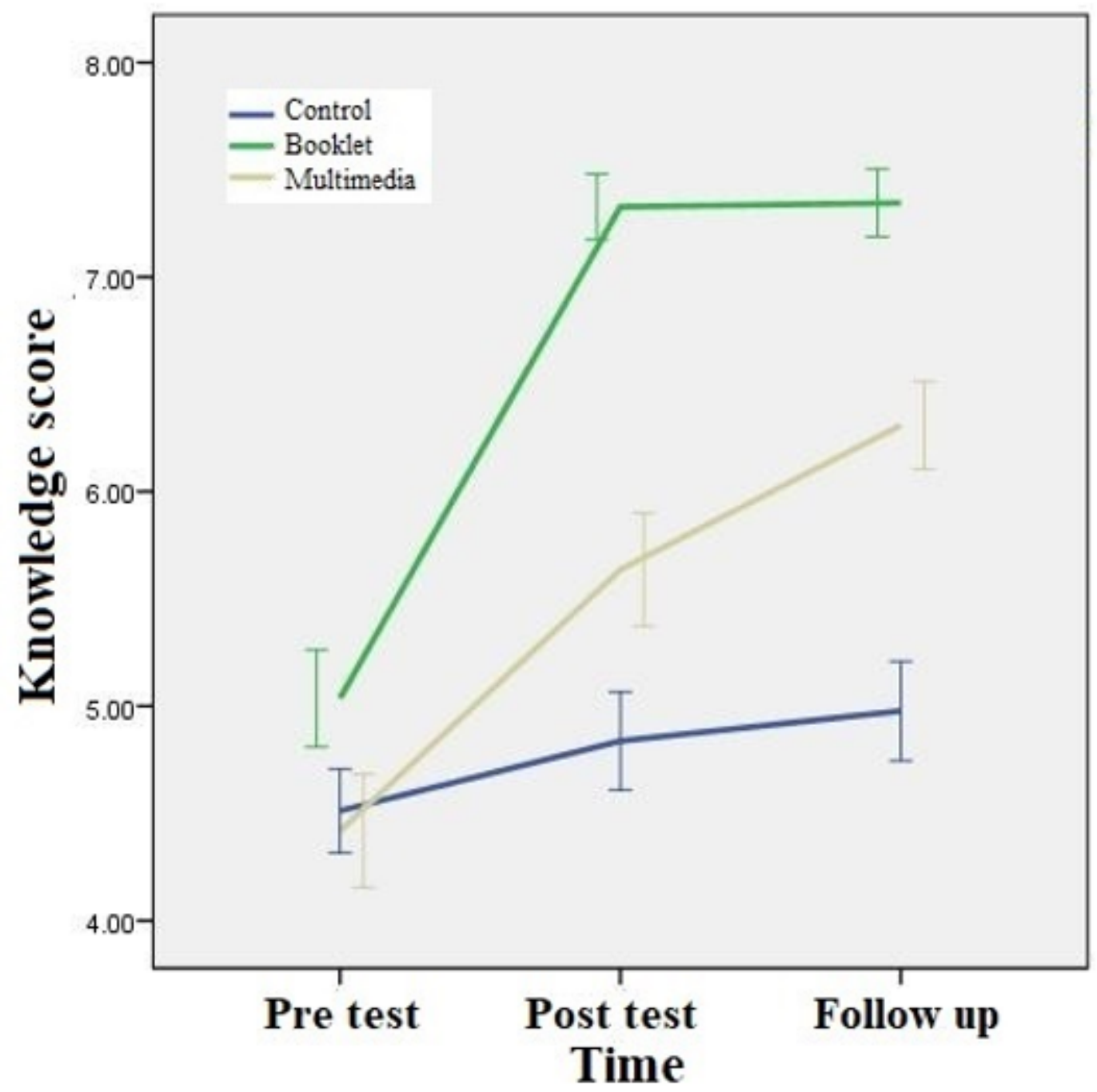

Figure 2

The trend of knowledge score in different groups 


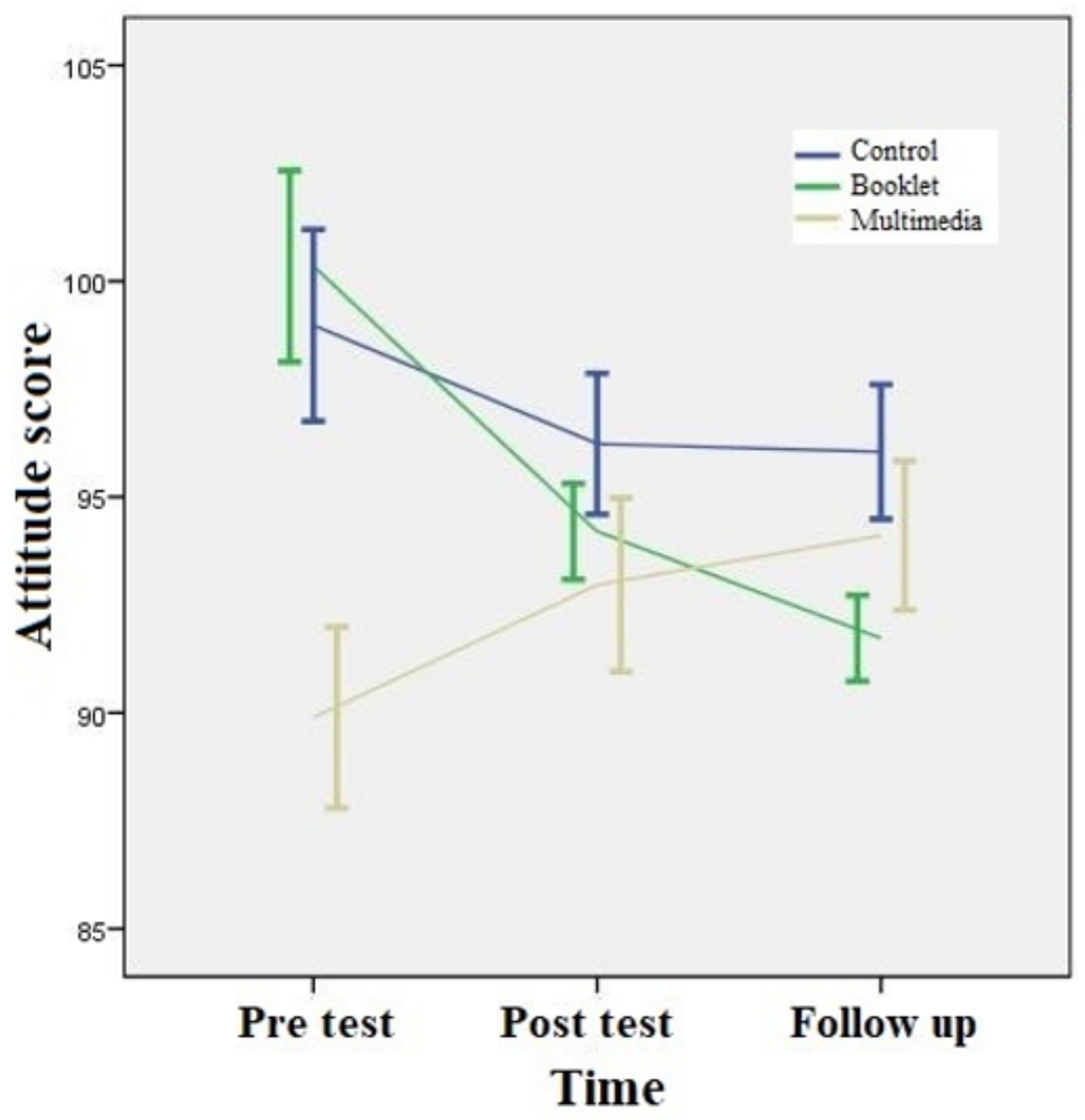

Figure 3

The trend of attitude score in different groups 


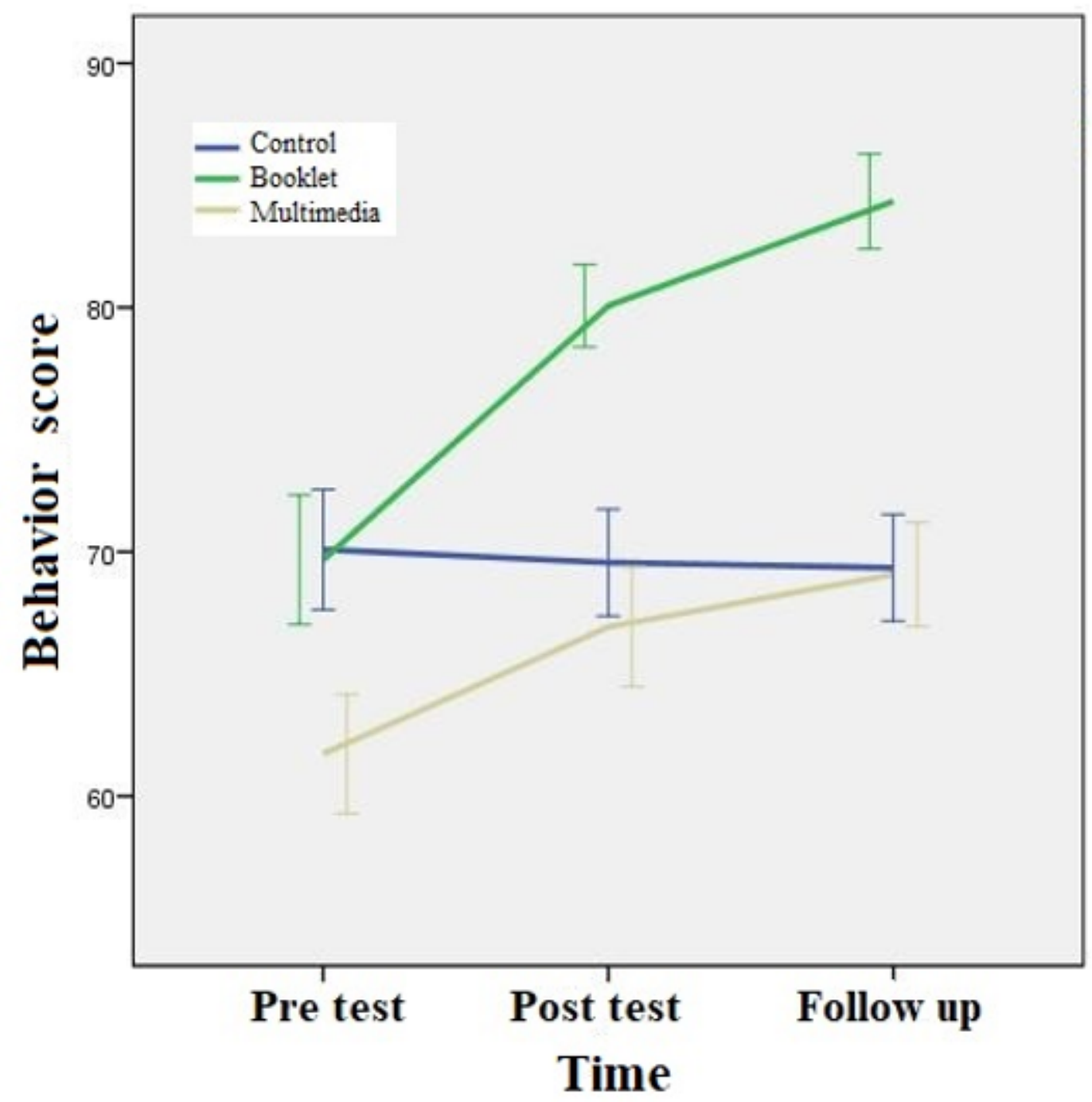

Figure 4

The trend of behavior score in different groups

\section{Supplementary Files}

This is a list of supplementary files associated with this preprint. Click to download.

- additionalfile1CONSORT2010Checklist.doc 